\title{
Italian Language as a Second Language Contrasting Analysis of Errors
}

\section{Eglantina Gerveni}

\author{
Universiteti "Ismail Qemali" i Vlores \\ Fakulteti i Shkencave Humane, Departamenti i Gjuheve te Huaja \\ egla_gerveni@yahoo.com
}

Doi:10.5901/mjss.2014.v5n6p423

\begin{abstract}
The process of acquiring, owning a foreign language at a satisfactory level, requires the creation of trust and security climate of both two actors who take part in the process, students and teachers. This study aims to highlight the difficulties, that Albanian students have in acquiring the Italian language. 181 pupils that constitute the sample of this study underwent a linguistic test. The test is designed in such a way to evidence in the fullest possible way difficulties and problems of the Albanian students. The results of the test are shown in the table as to be clear and to be analyzed statistically to better identify the fields, where they have bigger problems. Through this paper it is aimed and done a list of the students' mistakes if are analyzed the reasons which lead to errors and to give recommendations for the reduction of these errors.
\end{abstract}

Keywords: learning, Italian, second language LS, Albanian, errors.

\section{Introduction}

As a professor in the Department of Italian Language at the University of Vlora for a long time I had the opportunity to observe closely the performance of students of Italian language course. The fact that the students of High School Education as well as university students in speaking and writing make lots of mistakes, prompted me to undertake this study. It's true that their concept of thinking is higher. It's not only the level of linguistic competence in Italian Language, but also the types of errors that pushed me to follow them at high levels and to seek further explanations and possible practical solutions.

The study is based on the field of literature and a specific concrete research on the mistakes that Albanian students make when learning Italian as a foreign language. To avoid the risk of treating this argument in a simple sequence of errors recorded during a search, you would already have statistical purposes, the paper's main attention is focused primarily on the problem of analyzing the causes of errors and why make a mistake, then, to more fully in other problems such as typology, frequency, and finally, rectification and prevention, which would constitute the ultimate goal of a study for errors.

\section{Literature Related to the Argument}

The advanced idea in this dissertation has a starting point which originally support conceptions expressed in contrastive linguistics, however it goes further. Contrastive linguistics deals with differential analysis between the two languages, in order to give an exact complete picture of them for all ' symmetry ' and especially ' asymmetry ' that are in phonological and morphological-syntactical systems and languages, as an object of study. In asymmetry or differences between the two systems pay attention especially in contrastive linguistics. It has different goals from comparative linguistics which focus on particular elements of language and makes their description and function. On the contrary, work with contrastive linguistics, compares the two languages, having no connection between them, with the main purpose the study solutions to the problems of learning, and acquiring developing a teaching strategy.

Being implemented in the teaching of languages, it analyzes the differences between native language learners L1 and foreign language L2 and tends to improve teaching techniques, preventing, repairing and avoiding as much as possible negative effects of interference on native language L2, or another language acquired before. Contrastive linguistics is concerned with the practical use of forms in the communication process. It's search culminates with determination of interferences which occurs in the form of an error such as: "Disse che andrebbe " instead of " disse che sarebbe andato, under the influence of usage in Albanian, "he said he would come.", and ends with exercises for the correction of errors that are processed especially for those who can not overcome the obstacle that poses to the 
interference of $\mathrm{L} 1$.

Contrastive linguistics itself, is the result of a natural maturation of the scientific concept of linguistic analysis applied in the teaching of foreign languages. Usages of methodological and didactic purposes of contrastive linguistics are available for solving problems of language learning as Fries and R. Lado explain and wrote: "The best didactic material is that which is based on a scientific description of $L 2$, carefully compared with a description of students' native language. " According to him, learning a language is not hampered by structural difficulties, rather than rooted in long habits of native language, or in another language that is acquired earlier, and continuous interference of linguistic habits consolidated over them, now as a target language to learn. According to Lados "every pupil tends to pass any forms and meanings and distribution of meanings, of native language and culture in foreign language and culture, both in terms of usage in the instance when speaking or acting in culture, either receptive to the plan when trying to learn the language and understand the culture as they arise from natural speakers.

It is unchangeable the belief that teaching material for foreign language teaching should be scheduled based on contrastive analysis designed by Fies, Lado and Weireinch. There was a "crisis" of contrastive linguistics. This came from an excessive optimism from the beginning in the belief that could explain the whole process of learning a foreign language and grammatical changes to the rules of this language only through contrastive analysis. Lado has been criticized for an excessive mechanism about mistakes and learning problems, because not all errors are due to the influence practising in L1, or however caused by structural asymetry between L1 dhe L2. For this R. Titone writes: "contrastive analysis can not be always clearly applied in teaching, especially when using a direct methodological orientation or when we go to very young children where an open comparison, can cause confusion and uncertainty." (Psicolinguistica applicata, Applied Psycholinguistics, 1972, p 250) and continues "structural analysis approaches between L1 and L2 should be based not only on language but also on psycholinguistic and experimental basis". (the same page).

Implementation of contrastive linguistics in language teaching requires a certain didactic material for teaching L1, L2 through transition. It is assumed that where two languages structures match with each other at a certain point there are no acquisition problems. These problems will emerge in the case of structural asymmetry of two languages. This might be faced with a language that is not native, therefore a foreign language acquired before.

In the case of structural asymmetric between two languages, we encounter linguistic errors. Study them in terms of causes, typology, degree of repetition, correction or prevention, constitutes one of the fundamental tasks of contrastive linguistics.

About teaching that relies only on asymmetry between two languages, Schwarze notes that attentions are paid only to the changes, the student " risks to create a completely wrong opinion according to which L2 structures are different from those in L1 " (Bollettino del Centro per I' italiano all 'Estero, Trieste, 1974, p 44.) The case of errors is happened because it was thought that in L2 everything should be different, or out of concern and to fix all of that definitely.

\section{Description of Sample}

In this testing were eliminated first year students and the test was conducted with second and third years secondary schools "Xhelo", "Ali Demi", "Kemal Ataturk" and the Industrial High School in a total of 181 students. These schools develop learning Italian under a program approved by the Ministry of Education, unified for high schools. Given the program and classes developed in these years, as well as the overall level of language acquisition, I arrived earlier before starting a concrete work, concluded that their level of language proficiency was the first Italian average, suitable for the work that I intended to develop. The overall level of training is similar to students, and also is a matter for public schools and the same level of profile. There are teaching graduate teachers at the Faculty of Foreign Languages, University of Tirana, Vlora, the Italian branch of languages, but they have a long experience roughly the same work in secondary education and specifically to the teaching of the Italian language. Rates of progress in mastering Italian L2 are approximate among these schools.

\section{Description of Test}

The test organized was designed in this way. The test is constructed by simple sentences. Their content is related to everyday situations that students have worked such or similar to those made in class hours, performing exercises and other practices, which result in grammatical, lexical and phonetic cases(for phonetic already cases of double consonants). These are outlined and not all of them are used correctly. Students should find the wrong usage and 
replace it in correct use. Paid attention to their age and lack of experience in testing, the phonetic grammatical cases as I mentioned above, appear as highlighted when they are correct and when they are wrong. The wrong usage must be identified and regulated by the students, is the most recurring case of errors. It is also to be considered the wrong usage is appeared combined, when it comes to the use of inaccurate preposition in the preface as well as definite article simultaneously. It was such orientation in order to be more evident as the final score for each test sentence in particular and in general, aiming at the extraction of direct indicators and further statistical at the conclusion of testing. In the first sentence:

In Italia molte persone del sud vanno per lavorare al nord.

The case of the use of the verb Andare + preposition A + infinitive of the verb is most likely to be used wrong with the use of another preposition different from preposition A. It is often replaced and confused by the preposition PER. In the second sentence because of Albanian influence often have a wrong usage of the Italian preposition Da instead of another preposition. The presence of the sentence but in a different position of that same preposition PER is difficult in formulating a correct answer.

Problems encountered with the usage of verbs in Italian simple past are visible any times seem as an insurmountable obstacle for the teacher. In sentence 3 we have a common case of usage.

In the fourth case we have the combination of two verbs, but in the same subject. In the fifth case is fixed the usage of definite article of masculine gender before nouns which necessarily require GLI form. In 6 is the case of a masculine plural of exchange on a singular form. In 7 the case of this polite form in the wrong position with the second personal pronoun in plural. In 8 we suggest to use short form combined with full form. In 9 is given in case of phonetic usage of double consonant. In 10 it is for the same use of double consonant but with a final suggestion of a given verb. In 11 we have a lexical case for those usages where a student performs under a previously learned rule without further verification for special cases. In 13 we required the usage of modal verbs with intransitive verbs but in Albanian used by a particular word order. Check on the inaccuracies in the use of double consonants and in the case of verbs or adjectives behave in the most recent statements. For each case of constructing the request and sentences in the test we were aware of the reality of adaptability of the students in Italian Language and the conditions in which they learn that language.

\section{Interpretation of Statistical Data Accumulated from the Test}

Preposition 'a' when joins the verb ' andare ' with one another in the infinitive form as seen from the results of the test has a high incidence including students who have not fixed it and where the response is missing, about $40 \%$ compared with accurate responses. Due to such a high percentage is impact of Albanian language itself in output in Italian Language students. In Albanian instead of 'a ' is used preposition ' for'. Such an existing mistake is in higher stages of acquisition that occurs due to the fact that although there is nothing wrong happened to the comprehensibility of speech in Italian Language, the analogy to the expression of the same meaning causes an error since it doesn't compromises, remains the same.

The same justification can be made with the preposition ' for 'despite ' da ' in the second case presented. But the cumulative values show us a high degree of error from students than it was for the preposition 'a'. There is no doubt that proximity to Albanian rule underestimation of the Italian language rules used, and extent of usage according to the usage of Albanian in Italian, if not analogy of a deep meaning that is structurally indistinguishable that has the tendency to become a kind of analogy in the usage of prepositions.

Figure 3.to 181 tested only 15 of them have given the correct answer using the correct manner of indicative mood. Firstly I would put in the right order the gap of the linguistic construction in students language training. The result itself of their high errors reinforces this conclusion. There are many who do not use the proper match between verbs in Albanian language, not to speak of a foreign language. The second reason is the acquisition of incorrect or incomplete acquisition of Italian rule in the above mentioned usage. Since the general meaning is not compromised, this error also occurs in later stages of acquisition. Not encouraging the impact on the regulation of this error, is the fact that the Italian language is not taught in its own country where the daily impact in every moment leads to accuracy in speaking. In graph 4. $75.1 \%$ were those who did not perceive the wrong case, and a negligible number understood that error. The example is when two verbs in the same sentence refer to the same predicate. Such a negligible sensibility for this case which is repeated in many students' output in general, can not explain the fact that the way of speaking in Albanian, and because the students themselves are in Albania, have strongly influences which are noticeable in the way of speaking in 
Italian. They consistently use two articulated forms rather than one elaborate form of the first verb, and a second non articulate verb. Why do I think of influence in Albanian language? Between the two options, the one repeated in both cases is the mode of expression in Albanian.

To 5.1. $51 \%$ knew how to correct and give the correct answer to the definite article when using prefix ' gli ' in masculine plural that must be used before noun beginning with ' $s$ ' + consonant, in contrast to only $36 \%$ use accurate ' gli ' before masculine nouns that start with a vowel. Since $44 \%$ gave the wrong answer and about $20 \%$ didn't have an answer, indicates high levels of inaccuracy. Because of this error we take into consideration the gap of the rule fixing in most cases as well as definite articles analogy for masculine nouns.

In test 6, 67.4\% gave a correct answer when using definite form with masculine nouns ending in 'e'.

In n7.1 graph, we have only $5 \%$ to 181 tested that use the exact form of politeness and $72 \%$ couldn't distinguish the wrong form of speaking for politeness form..Actually this problem requires the awareness of teachers in the early stages for the unique improvement of the correct form than might achieve the results that are difficult to be recovered. The impact of the way of expression in Albanian causes its portage in Italian with the second pronoun plural. And lack of perseverance itself from the part of teachers in this regard, makes that second personal plural is used in Italian as a form of politeness, as well. As for the results of 7.2, I can say that it is simply a problem of acquisition that proves the rule and self restrained score of $44 \%$ correct answers. Correct use of the second personal pronoun in plural with relevant verbal form in the second part of the sentence was filed in the first rate, if there is a space for analogy and for such cases. In figure 8, it mirrors the use of the personal pronoun forms. In 181 testing, 101 were answered correctly, so about $56 \%$. Although it can be considered again a good percentage suggests that the error in the answer depends on a certain analogy to the student trying to decide within the language without making a further distinction and mastering the difference between the personal pronoun forms.

In graphs 9 and 10, usage of the correct or incorrect double consonants. Percentages of responses are flexible and so is the general realization usage by students. The use of double consonants in Albanian is quite different from that of the Italian language. One of the reasons for a restrained impact is the confusion caused to students themselves in Albanian as a double ' || ' which differs from the ' I ' which refer to two different phonemes. This does not happen in Italian, at least in this case. But when we have a single ' $n$ ' or double gives us a completely different meaning of the word. I am of the opinion that there is little impact from the Albanian language, but that is not always the main cause. Because' $n$ ' is and wrong appropriation of writing the word correctly since the beginning. Another cause might be and the similarity or generalization in other words.

At 11, in the case of error now a different nature. $51.4 \%$ have accurate answers. Error of such a nature stems in analogies with other forms that the word gets or similar forms. If you think that the case is a regular verb of the present indicative mood, the result may not be satisfactory.

In graph 12, is the outcome mirrors with irregular participle. $55 \%$ are accurate, they recognized the error and fixed it correctly.

In graph 13, $23 \%$ are accurate while $40 \%$ are wrong, about of $3 \%$ were unfixable. The cause of wrong usage of auxiliary verbs ' avere ' and ' essere ' with verbs in Italian, whether transitive or intransitive, is the impact of using the intransitive verbs in Albanian for auxiliary verb ' have ' in the recent formation composed. The teacher should emphasize in this direction in order that the student would be able firstly to distinguish not implement the rule of the Albanian language by transferring the expression in Italian.

In graph 14, we have the case of composed verbs of transition and auxiliary verbs. $54 \%$ correct and wrong about $45 \%$ missing. This is a balanced case. Stabilization of the correct use of auxiliary verb in times of composed verbs of transition is a problem as long as the student is in an intermediate stage of detachment from Albanian but that still has not gone completely in the other language. This is a difficult stage because students acquire language in terms of a favorable environment for the Albanian language. And in the case of 14.2 where the auxiliary verb is used correctly, a not stable percentage to give a solid answer. This proves that the correct use of auxiliary verbs by our students at this level of appropriation is troubled.

In graphs 15 and 16 are reflected further results which show that the use of double consonants there is always a problem. And I will give another explanation. The cause may be required to another source of phonetic nature. If the pronunciation of double consonants at the beginning will become properly the risk might be lower of error in writing.

Sentence:

- 1 Generally the wrong case of the verb andare + preposition a. But there is another problem. Lavorare al nord, a good percentage has remedied by removing the definite form of the preposition before nord. The Albanian language is influential because it is indefinite. It is a mistake that can be eliminated very quickly.

- Almost all do not distinguish in Italian is said per quale strada not da quale strada. It's an interference in 
Albanian way of speaking. There are attempts to replace" a casa" to "in casa", as a consequence of a stretch in understanding of the similar meaning in Albanian as a preposition that expresses a direct preposition" in". The preference for using 'in' instead of ' 'a' may be a fossilized mistake which we encounter after they have achieved high levels of Italian language acquisition.

- $\quad$ 3.In reconciliation of times there are different problems with the inability to be aware of further mistakes and fix them. This kind of error is linked to a general gap in the formation of our language students who have never learned what a verb expresses a certain time and how they relate together in sentences, in the native language as well as in foreign language.

- $\quad$ 4. There is no students who is able to make the difference, in this case, the combination of two verbs in Italian language where as it comes to an action that the subject itself performs only the first verb is in the proper person and in the proper number of the subject, and second verb is in infinitive and it connects to the preposition 'di'. In Albanian language they are expressed differently meanwhile in Italian it is a fixed form in the organization of sentence. It is a mistake that threatens to fossilize if no the right attention.

- With masculine plural prefix of definite article - gli -is indispensable before nouns. I think based on my findings that students understand that is used only before masculine nouns that start with vowels. But there is an encouraging situation and try to use the appropriate article.

- $\quad 6.1$ saw sometimes in tests errors recorrected and convert in feminine version. In Albanian is the feminine gender for the word flower, while in Italian is masculine. So gender is a shift from the impact of the Albanian language at this level.

- $\quad$ 7.They have recorrect - Voi - but not verb in the second -person plural. Voi is generally corrected but not generally substituted by - Lei. This makes me think that they use themselves a second person plural in Albanian to form politeness and the elimination of - Voi - shows that they have not yet realized that courtesy form is singular third person. They don't even realize when we have two variants in one and a plural case given in contextual meaning.

- In general they understand that personal pronoun - to - must not stand and replace putting short form'ti' attached to - infinitive after the verb chiamare.

- $\quad$ They proved to be sensible toward the double consonant 'bella' but I understand that this is due to the adjective used more often and therefore more embedded. It is not the same in other pupils' achievements.

- $\quad$ so I can justify to form the third person piace of piacere.

- $\quad$ in the correction of lexical error 'leggiono' is a special situation. It's a good that they who have repaired it right but wrong again in double consonant - $g$ - by giving it as single' legono' which is wrong. But anyway there is lexical error correction in this sentence.

- $\quad$ Remedy is not always enough answer and I found that two - s - Italian has a completely different meaning from that of the past causative 'preso'. I do not think that they read - s - as voiced, which makes me think in other inaccuracies in the usage of double consonants and a lack of familiarity with the regulations of the pronunciation of words with one or two of which have two corresponding variants voiced and not imposing them.

- $\quad$ 13. There are few students who are precisely in compound verb 'intervenire' and requires the verb essere unlike the correspondent verb in Albanian 'intervene'. The beginning is a mistake that remains long and can fossilize in student achievement. Is a lack of linguistic training that helps to inculcate such use.

- $\quad$ Even with the verb entrare many students think about the reasons listed above with auxiliary verb avere in times of compound.

- $\quad$ 15-16. in general, they realize that chiamo is written with one- $m$ - and less necessario is written with two s-and $a-c$. 


\section{Graphic Test Data}

6.1 Preposition "a"

\begin{tabular}{|c|c|c|c|c|c|}
\hline & & Density & Percentage & $\begin{array}{l}\text { Available } \\
\text { Percentage }\end{array}$ & $\begin{array}{c}\text { Accumulated } \\
\text { Percentage }\end{array}$ \\
\hline \multirow{5}{*}{ Available } & Missing & 18 & 9.9 & & 9.9 \\
\hline & Wrong & 50 & 27.6 & 27.6 & 37.6 \\
\hline & Undone & 6 & 3.3 & 3.3 & 40.9 \\
\hline & Right & 107 & 59.1 & 59.1 & 100.0 \\
\hline & In Total & 181 & $100 . c$ & $100 . c$ & \\
\hline
\end{tabular}

6.2 Preposition "per"

\begin{tabular}{|c|c|c|c|c|c|}
\hline & & Density & $\begin{array}{l}\text { Percentag } \\
e\end{array}$ & $\begin{array}{l}\text { Avaliable } \\
\text { Percentage }\end{array}$ & $\begin{array}{l}\text { Accumulated } \\
\text { Percentage }\end{array}$ \\
\hline \multirow{5}{*}{ Available } & Missing & 36 & 19.9 & 19.9 & 19.9 \\
\hline & Wrong & 132 & 72.9 & 72.9 & 92.8 \\
\hline & Undone & 4 & 2.2 & 2.2 & 95.0 \\
\hline & Right & 9 & 5.0 & 5.0 & 100.0 \\
\hline & In total & 181 & 100.0 & 100.0 & \\
\hline
\end{tabular}

6.3 Question3: Adaption of indicative mood

\begin{tabular}{|c|c|c|c|c|c|}
\hline & & Density & Percentage & $\begin{array}{l}\text { Available } \\
\text { Percentage }\end{array}$ & $\begin{array}{l}\text { Accumulated } \\
\text { Percentage }\end{array}$ \\
\hline \multirow{4}{*}{ Aveilable } & Missing & 37 & 20.4 & 20.4 & 20.4 \\
\hline & Wrong & 129 & 71.3 & 71.3 & 91.7 \\
\hline & $\begin{array}{l}\text { Undone } \\
\text { Right }\end{array}$ & 15 & 8.3 & 8.3 & 100.0 \\
\hline & In total & 181 & 100.0 & 100.0 & \\
\hline
\end{tabular}

6.4 Question 4: The same subject

\begin{tabular}{|c|r|r|r|r|}
\hline & Density & Percentage & $\begin{array}{l}\text { Available } \\
\text { Percentage }\end{array}$ & $\begin{array}{l}\text { Accumulate } \\
\text { Percentage }\end{array}$ \\
\hline Available Mrong & 42 & 23.2 & 23.2 & 23.2 \\
Correct & 136 & 75.1 & 75.1 & 98.3 \\
In total & 3 & 1.7 & 1.7 & 100.0 \\
\hline
\end{tabular}

6.5 Question 5: 1Masculine definite article "gli"

\begin{tabular}{|c|c|c|c|c|c|}
\hline & Density & Derrentage & $\begin{array}{l}\text { Available } \\
\text { Derrentage }\end{array}$ & \multirow{2}{*}{ 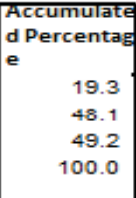 } \\
\hline Avallable & $\begin{array}{c}\text { Missing } \\
\text { Wrong } \\
\text { Undone } \\
\text { Correct } \\
\text { In total } \\
\end{array}$ & $\begin{array}{r}35 \\
52 \\
2 \\
92 \\
181\end{array}$ & $\begin{array}{r}19.3 \\
28.7 \\
1.1 \\
50.8 \\
100.0\end{array}$ & $\begin{array}{r}19.3 \\
28.7 \\
1.1 \\
50.8 \\
100.0\end{array}$ & \\
\hline
\end{tabular}

6.6 Question 5:2

\begin{tabular}{|c|c|c|c|c|c|}
\hline & & Density & Percentage & $\begin{array}{l}\text { Available } \\
\text { Percentage }\end{array}$ & $\begin{array}{l}\text { Accumulate } \\
\text { Percentage }\end{array}$ \\
\hline \multirow{4}{*}{ Available } & Missing & 35 & 19.3 & 19.3 & 19.3 \\
\hline & Wrong & 80 & 44.2 & 44.2 & 63.5 \\
\hline & $c o$ & 66 & 36.5 & 36.5 & 100.0 \\
\hline & In total & 181 & 100.0 & 100.0 & \\
\hline
\end{tabular}


6.7 Question 6.

\begin{tabular}{|c|c|c|c|c|c|}
\hline & & Density & Percenlage & $\begin{array}{l}\text { Availablc } \\
\text { Percentage }\end{array}$ & $\begin{array}{l}\text { Accumulatc } \\
\text { Percentage }\end{array}$ \\
\hline \multirow{5}{*}{ Available } & Missing & 35 & 19.3 & 19.3 & 19.3 \\
\hline & Wrong & 20 & 11.0 & 11.0 & 30.4 \\
\hline & Undone & 4 & 2.2 & 2.2 & 32.6 \\
\hline & Cuiteul & 122 & 67.4 & 67.4 & 100.0 \\
\hline & Intatal & 181 & 100.0 & 100.0 & \\
\hline
\end{tabular}

6.8 Question 7.1: Courtesy form

\begin{tabular}{|l|l|l|l|l|}
\hline & Density & Percentage & $\begin{array}{l}\text { Available } \\
\text { percentage }\end{array}$ & $\begin{array}{l}\text { Accumulatecd } \\
\text { Percentage }\end{array}$ \\
\hline Available Missing & 40 & 22.1 & 22.1 & 22.1 \\
Wrong & 130 & 71.8 & 71.8 & 93.9 \\
Undone & 2 & 1.1 & 1.1 & 95.0 \\
Correct & 9 & 5.0 & 5.0 & 100.0 \\
In total & 181 & 100.0 & 100.0 & \\
\hline
\end{tabular}

6.9 Question 7.2 Second person in plural

\begin{tabular}{|c|c|c|c|c|c|}
\hline & & Density & Percentage & \begin{tabular}{|l} 
Available \\
Percentage
\end{tabular} & $\begin{array}{l}\text { Accumulateg } \\
\text { Percentage }\end{array}$ \\
\hline \multirow{6}{*}{ Available } & & 40 & 22.1 & 22.1 & 22.1 \\
\hline & Missing & 45 & 24.9 & 24.9 & 47.0 \\
\hline & Wrong & 2 & 1.1 & 1.1 & 48.1 \\
\hline & Undone & 14 & 7.7 & 7.7 & 55.8 \\
\hline & Correct & 80 & 44.2 & 44.2 & 100.0 \\
\hline & In total & 181 & 100.0 & 100.0 & \\
\hline
\end{tabular}

6.10 Question 8: Personal pronoun

\begin{tabular}{|c|c|c|c|c|c|}
\hline & & Density & Percentage & $\begin{array}{l}\text { Available } \\
\text { Percentage }\end{array}$ & $\begin{array}{l}\text { Accumulated } \\
\text { Percentage }\end{array}$ \\
\hline Available & $\begin{array}{l}\text { Missing } \\
\text { Wrong } \\
\text { Undone } \\
\text { Correct } \\
\text { In total } \\
\end{array}$ & $\begin{array}{r}35 \\
35 \\
10 \\
101 \\
181 \\
\end{array}$ & $\begin{array}{r}19.3 \\
19.3 \\
5.5 \\
55.8 \\
100.0 \\
\end{array}$ & $\begin{array}{r}19.3 \\
19.3 \\
5.5 \\
55.8 \\
100.0 \\
\end{array}$ & $\begin{array}{r}19.3 \\
38.7 \\
44.2 \\
100.0\end{array}$ \\
\hline
\end{tabular}

6.11 Question 9:Double consonants

\begin{tabular}{|c|c|c|c|c|c|}
\hline & & Density & Percentage & \begin{tabular}{|l} 
Available \\
Percentage
\end{tabular} & \begin{tabular}{|l|} 
Accumulated \\
Percentage
\end{tabular} \\
\hline \multirow{5}{*}{ Available } & Missing & 39 & 21.5 & 21.5 & 21.5 \\
\hline & Wrong & 25 & 13.8 & 13.8 & 35.4 \\
\hline & Undone & 2 & 1.1 & 1.1 & 38.5 \\
\hline & Correct & 115 & 63.5 & 63.5 & 100.0 \\
\hline & In total & 181 & 100.0 & 100.0 & \\
\hline
\end{tabular}

6.12 Question 10: Double consonants in verbs

\begin{tabular}{|r|r|r|r|r|r|}
\hline & & Density & Percentage & $\begin{array}{l}\text { Available } \\
\text { Percentage }\end{array}$ & $\begin{array}{l}\text { Accumulated } \\
\text { Percentage }\end{array}$ \\
\hline \multirow{4}{*}{ Available } & Missing & 42 & 23.2 & 23.2 & 23.2 \\
& Wrong & 56 & 30.9 & 30.9 & 54.1 \\
& Undone & 1 & .6 & .6 & 54.7 \\
& Correct & 82 & 45.3 & 45.3 & 100.0 \\
& In total & 181 & 100.0 & 100.0 & \\
\hline
\end{tabular}


6.13 Question11: Lexical error

\begin{tabular}{|c|c|c|c|c|c|}
\hline & & Density & Percentage & $\begin{array}{l}\text { Available } \\
\text { Percentage }\end{array}$ & $\begin{array}{l}\text { Accumulated } \\
\text { Percentage }\end{array}$ \\
\hline \multirow{5}{*}{ Available } & Missing & 50 & 27.6 & 27.6 & 27.6 \\
\hline & Wrong & 34 & 18.8 & 18.8 & 46.4 \\
\hline & Undone & 4 & 2.2 & 2.2 & 48.6 \\
\hline & Correct & 93 & 51.4 & 51.4 & 100.0 \\
\hline & Intotal & 181 & 100.0 & 100.0 & \\
\hline
\end{tabular}

6.14 Question12: Irregular participle

\begin{tabular}{|c|c|c|c|c|c|}
\hline & & Density & Percentage & $\begin{array}{l}\text { Available } \\
\text { Percentage }\end{array}$ & $\begin{array}{l}\text { Acculumate } \\
\text { Percentage }\end{array}$ \\
\hline & Missing & 48 & 28.5 & 28.5 & 26.5 \\
\hline \multirow{4}{*}{ Available } & Wrong & 27 & 14.9 & 14.9 & 41.4 \\
\hline & Undone & 6 & 3.3 & 3.3 & 44.8 \\
\hline & Correct & 100 & 55.2 & 55.2 & 100.0 \\
\hline & In total & 181 & 100.0 & 100.0 & \\
\hline
\end{tabular}

6.15 Question 13: Semi modal Auxiliary verbs

\begin{tabular}{|c|r|r|r|l|r|}
\hline & \multicolumn{2}{|l|}{$\begin{array}{l}\text { Density } \\
\text { 1 }\end{array}$} & Percentage & $\begin{array}{l}\text { Available } \\
\text { Percentage }\end{array}$ & $\begin{array}{l}\text { Accumulated } \\
\text { Percentage }\end{array}$ \\
\hline Available & Missing & 64 & 35.4 & 35.4 & 35.4 \\
& Wrong & 72 & 39.8 & 39.8 & 75.1 \\
& Undone & 4 & 2.2 & 2.2 & 77.3 \\
& Correct & 41 & 22.7 & 22.7 & 100.0 \\
& In total & 181 & 100.0 & 100.0 & \\
\hline
\end{tabular}

6.16 Question 14: Auxiliary verbs and verbs of transition

\begin{tabular}{|c|c|c|c|c|c|}
\hline & & Density & Percentage & $\begin{array}{l}\text { Available } \\
\text { Percentage }\end{array}$ & $\begin{array}{l}\text { Accumulated } \\
\text { Percentage }\end{array}$ \\
\hline$\overline{\text { Available }}$ & $\begin{array}{l}\text { Missing } \\
\text { Wrong } \\
\text { Correct } \\
\text { In total }\end{array}$ & $\begin{array}{r}56 \\
28 \\
97 \\
181 \\
\end{array}$ & $\begin{array}{r}30.9 \\
15.5 \\
53.6 \\
100.0 \\
\end{array}$ & $\begin{array}{r}30.9 \\
15.5 \\
53.6 \\
100.0 \\
\end{array}$ & $\begin{array}{r}30.9 \\
46.4 \\
100.0\end{array}$ \\
\hline
\end{tabular}

6.17 Question 15:Double consonants in verbal forms

\begin{tabular}{|c|c|c|c|c|c|}
\hline & & Density & Percentage & $\begin{array}{l}\text { Available } \\
\text { Percentage }\end{array}$ & $\begin{array}{l}\text { Accumulate } \\
\text { Percentage }\end{array}$ \\
\hline Available & $\begin{array}{l}\text { Missing } \\
\text { Wrong } \\
\text { Undone } \\
\text { Correct } \\
\text { In total }\end{array}$ & $\begin{array}{r}63 \\
35 \\
1 \\
82 \\
181 \\
\end{array}$ & $\begin{array}{r}34.8 \\
19.3 \\
.6 \\
45.3 \\
100.0\end{array}$ & $\begin{array}{r}34.8 \\
19.3 \\
.6 \\
45.3 \\
100.0\end{array}$ & $\begin{array}{r}34.8 \\
54.1 \\
54.7 \\
100.0\end{array}$ \\
\hline
\end{tabular}

6.18 Question 16: Double consonants in adjectives

\begin{tabular}{|c|r|r|r|r|}
\hline & Density & Percentage & $\begin{array}{l}\text { Available } \\
\text { Percentage }\end{array}$ & $\begin{array}{l}\text { Accumulated } \\
\text { Percentage }\end{array}$ \\
\hline Missing & 92 & 50.8 & 50.8 & 50.8 \\
Wrong & 40 & 22.1 & 22.1 & 72.9 \\
Correct & 49 & 27.1 & 27.1 & 100.0 \\
In total & 181 & 100.0 & 100.0 & \\
\hline
\end{tabular}




\section{Conclusions and Recommendations}

1. It is more appropriate to draw conclusions from real data than to make predictions on hypothetical data. In contrast to error analysis, approach analysis, refuses the widespread perception that it is easier to achieve active power of a foreign language similar to native language. In fact, the results of the analysis indicate errors at times and make mistakes in the symmetries in case of similarity between L1 and L2 after the biggest temptation of students to bring into light grammatical shapes and lexical elements of their language.

2. Error analysis should be closely aware of circumstances that have supported them (the age of the students, using text, timetable, etc.)

3. Not all typical errors are equally important and serious. Typically the most common mistakes are the ones that should disturb the teacher. As studies show three or four mistakes most frequent for each linguistic group significantly exceed twenty or thirty numbers to become one after another getting together.

4. As understanding the way grammatical mechanism operates, does not mean automatic acquisition of language skills, also should explain to them the cause of the error and explain them again that grammatical argument does not solve the problem. Mistakes are not a problem as those of competence rather than those of output, for whom excess is an additional explanation. Such errors can be eliminated by doing exercises that are repeated until overlearning.

5. The key problem lies in correcting exercises, better in those preventive, that tend to reduce the risk of errors.

6. Ensuring which are more typical or frequent mistakes, teacher warns the elder students more exposed at the risk of errors, however avoiding falling into the formalization of traditional grammar translation method. When there are not elder students, teachers should be reserved not make clear references to the risk of errors and will use the data obtained from analysis of errors only for the processing of didactic material that will prevent common mistakes.

7. The study for the typology of errors typically asserts that no errors for each language or class at a starting point. (here adding mistakes by individual factors). For this reason should be evaluated and appreciated the individual work as carefully as possible especially with self-fixing errors tabs. In fact, the amount of personal problems learning acquisition, gives teachers a typical problem within the class. The teacher should encourage the student to do individual work.

8. None of the studies for mistakes should not be considered final. If it is true that the problems of today's students are thought to be problems of tomorrow's students, is equally true that the problems can vary from class to class, according to the human element and circumstances where teaching is conducted and takes place.

\section{References}

Balboni P.1994, Didatticadellitaliano A Stranieri,Roma, Bonacci.

Balboni P. 2008,Imparare Le Lingue Straniere,Venezia,Marsilio.

Bettoni C.2001,Imparare Un 'Altra Lingua,Roma-Bari,Laterza.

Bettoni C.2006, Usare Un Altra Lingua, Roma -Bari,Laterza.

Krashen S.1981, Second Language Acquisition And Second Language

Learning, Oxford, Pergamon Press.

Lado R.1961,Language Testing, London,Longman.

Mezzadri M. 2006,Integrazione Linguistica In Europa,II Quadro Comune

Di Riferimento Per Le Lingue.Torino,Utet.

Nunan D. 1992, Research Methods In Language Learning And Teaching,Cambridge, Cambridge University Press.

Palloti G. 1998, La Seconda Lingua,Milano,Bompiani.

Selinker,L. 1972, Interlanguage <<|ral >> N. 10.

Vedovelli M.2002,L'italiano Degli Stranieri.Storia Attualita,Prospettive Roma,Carocci.

Vedovelli M. 2006, Italiano In Italia Italiano Nel Mondo, <<llsa Italiano A Stranieri 〉>. 
